\title{
Acute presentation of Leriche syndrome in United Arab Emirates: A case report
}

\section{Omar Sherif Askar, Abdel H Noureldin, Satish Chandrasekhar Nair}

\begin{abstract}
Introduction: Aortoiliac occlusive disease or Leriche syndrome is a serious condition in which patients usually present with the triad of chronic symptoms consisting of claudication of the buttocks and thighs, absent or decreased femoral pulses, and impotence. Our report, first from the gulf region, describes an acute severe presentation of Leriche syndrome which resulted in mortality. This case report helps emergency roomphysiciansinthe diagnosis and management of acute presentation of aortoiliac occlusive disease, especially in international settings. Case Report: A 32-year-old male presented to our emergency department as a referral from another hospital. He complained of severe back pain and bilateral leg weakness. The patient had two cardiac arrests, first one was in the operating room and died after the second arrest two days later in ICU. Conclusion: It is critical that the examining physician place aortoiliac occlusive disease high on the differential during patient assessment, given that the rapidity of diagnosis and further management has significant impact on morbidity and mortality.
\end{abstract}

Omar Sherif Askar ${ }^{1}$, Abdel H Noureldin², Satish Chandrasekhar $\mathrm{Nair}^{3}$

Affiliations: ${ }^{1} E R$ Resident, Academic Affairs Department, Tawam Hospital, Al Ain, Emirates of Abu Dhabi, United Arab Emirates; ${ }^{2}$ Consultant Physician, ER-Trauma CenterMEERTC (Dep), Tawam Hospital, Al Ain, Emirates of Abu Dhabi, United Arab Emirates; ${ }^{3}$ Senior Specialist, Head of Clinical Research, Academic Affairs Department, Tawam Hospital, Al Ain, Emirates of Abu Dhabi, United Arab Emirates. Corresponding Author: Omar Sherif Riad Askar, MD, Al Ain, Emirates of Abu Dhabi, United Arab Emirates. Postal Code: 222146; Ph: +971-50-2198600, Fax: +97137677634; Email: omaraskar0671@gmail.com

Received: 28 November 2012

Accepted: 11 January 2014

Published: 24 May 2014
Keywords: Leriche syndrome, Aortoiliac occlusion, Severe back pain

\section{How to cite this article}

Askar OS, Noureldin AH, Nair SC. Acute presentation of Leriche syndrome in the United Arab Emirates: A case report. Case Reports International 2014;3:69.

Article ID: 100004CRINTOA2014

$* * * * * * * * *$

doi:10.5348/crint-2014-4-CR-2

\section{INTRODUCTION}

In patients with atherosclerosis, plaque formation commonly occurs in the infrarenal aorta and iliac arteries. Symptoms usually start when the plaques obstruct blood flow or break apart and embolize to more distal blood vessels. Large plaques may cause narrowing of the arterial lumen and reduce blood flow to the extremities. Recognition of the risk factors that predispose to development of arterial lesions is critical and enables the treating physician to prescribe non-operative management that can decrease mortality and morbidity if done in a timely manner [1]. To date, there is no report of aortoiliac occlusive disease (Leriche syndrome) from the middleeast, particularly the Gulf Cooperation Council (GCC) or gulf countries. Conversely, a study from Turkey indicated that Leriche syndrome with diabetes mellitus is more likely to have advanced coronary disease than those without [2].

To the best of our knowledge, our case of Leriche syndrome from the emergency department of Tawam hospital, a 468-bed, ACGME-I accredited, tertiary care academic medical center in the UAE, is the first from the gulf region. 


\section{CASE REPORT}

A 32-year-old British male presented to our emergency department as a referral from an outlying hospital. He was complaining of severe back pain and bilateral leg weakness. The onset was sudden and started an hour prior to arrival at the referring hospital. Associated symptoms included chest pain, bilateral upper and lower limb tingling, numbness and weakness. Further questioning also revealed a history of impotence for the past few months. Past medical and surgical history was significant for tetralogy of Fallot that was surgically treated at the age of ten years. Vitals on arrival were blood pressure $63 / 34 \mathrm{mmHg}$, temperature $35^{\circ} \mathrm{C}$, pulse 118 beats/minute, respiratory rate 18 /minute and oxygen saturation $100 \%$ on room air.

On initial examination the patient was observed to be in severe distress, pale and diaphoretic. Chest auscultation was positive for decreased breath sounds on right upper, middle and lower lobes. The patient was also found to have severe bilateral lower limb weakness (left $2 / 5$ ), better than right (1/5), pale skin, loss of sensation, and no palpable pulses bilaterally below both femoral arteries. As the patient was showing signs of hypovolemic shock, he was fitted with two large bore IV cannula and started on multiple normal saline boluses and empirically received two units of packed red blood cells (subsequent hemoglobin level $17.5 \mathrm{~g} / \mathrm{L}$ ). He was also covered with a heating blanket to counter hypothermia. A quick, portable antero-posterior view chest X-ray demonstrated right side diffuse parenchymal consolidation with pleural effusion. Arterial blood gas results showed pH 7.056, $\mathrm{PCO} 246.7$ $\mathrm{mmHg}$, $\mathrm{PO} 291.1 \mathrm{mmHg}$, bicarbonate $12 \mathrm{mmol} / \mathrm{L}$, base excess - $17.4 \mathrm{mmol} / \mathrm{L}$, sodium $139.7 \mathrm{mmol} / \mathrm{L}$, potassium $5.5 \mathrm{mmol} / \mathrm{L}$, calcium $1.19 \mathrm{mmol} / \mathrm{L}$, glucose $4.8 \mathrm{mmol} / \mathrm{L}$, and lactate $10.3 \mathrm{mmol} / \mathrm{L}$. Laboratory results revealed several abnormalities but were most remarkable for an elevated Troponin-I $0.25 \mathrm{ng} / \mathrm{mL}$, B-type natriuretic peptide $1.008 \mathrm{pg} / \mathrm{mL}$, creatinine $164 \mu \mathrm{mol} / \mathrm{L}$ and urea 8.8 $\mathrm{mmol} / \mathrm{L}$. Vascular surgery and cardiology services were consulted to evaluate possibilities of aortic dissection or a vaso-occlusive thrombus.

Following stabilization of the patient's blood pressure at $99 / 83 \mathrm{mmHg}$, he underwent emergent computed tomography (CT) scan with angiography. Imaging data demonstrated a saddle embolus in the distal aorta at the level of L4, extending into the right and left common iliac arteries (Figures 1 and 2), along with a suspicious embolus in the left renal artery at the mid-section causing an extensive renal infarction, and a splenic infarction at the ventral lower pole. There was also a massive cardiomegaly with dilated right ventricle. These findings confirmed the diagnosis of aortoiliac occlusion. The patient was immediately transferred to the operating theatre by the vascular surgeons, he underwent an embolectomy. The patient had cardiac arrest on the operating table with a cardiac rhythm of pulseless electrical activity (PEA) while waiting for an intensive care unit (ICU) bed to be prepared. Cardiopulmonary resuscitation (CPR) was performed with successful achievement of return of spontaneous circulation (ROSC).

The patient was transferred to the ICU on light sedation. He was responding to pain. A bedside echocardiogram was performed by the attending cardiologist that demonstrated severe biventricular dysfunction and pulmonary hypertension. The patient unfortunately arrested again in the ICU two days later while on three inotropes. Cardiopulmonary resuscitation was unsuccessful on this occasion and the patient was pronounced dead.

\section{DISCUSSION}

Rene Leriche in 1923 described occlusion of the distal aorta and iliac arteries, which includes both acute and chronic forms of the disease $[1,3]$. Acute Leriche syndrome most commonly presents with symptoms of

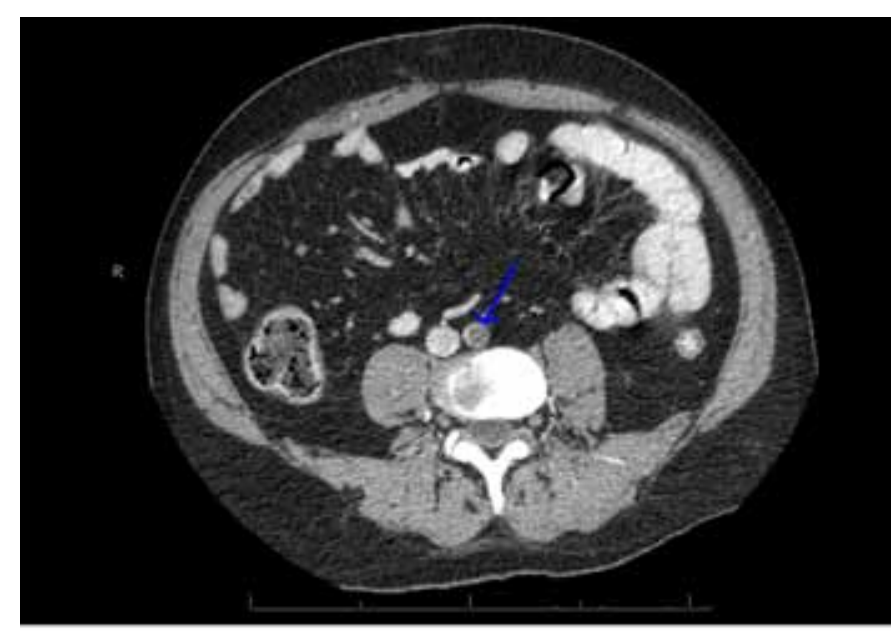

Figure 1: Computed tomography scan after administration of contrast demonstrating complete occlusion of abdominal aorta by the thrombus (arrow indicates occluded aorta).

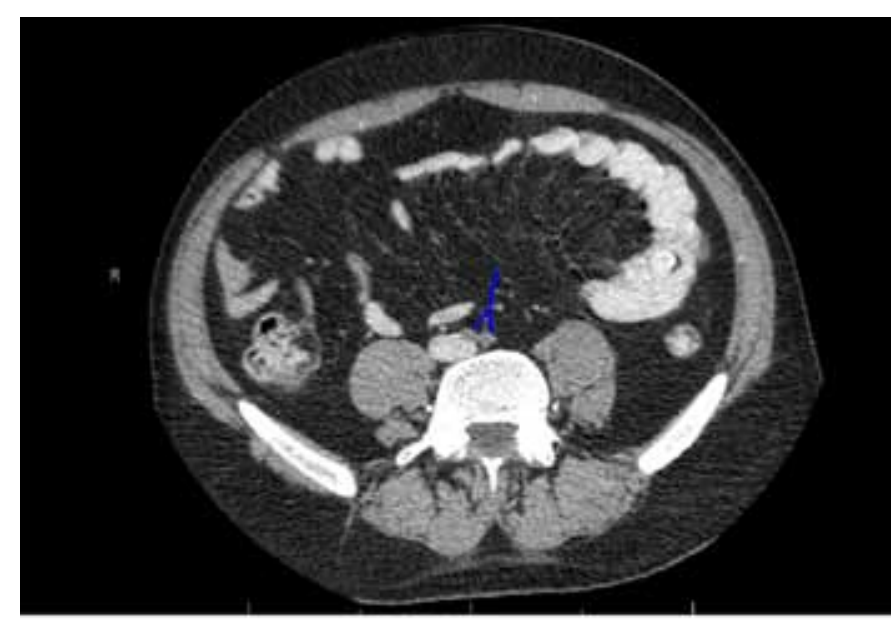

Figure 2: Computed tomography scan after administration of contrast demonstrating extension of the thrombus into right and left common iliac arteries with complete occlusion (arrow indicates common iliac arteries). 
acute limb ischemia. Clinical symptoms are dependent upon the level of arterial occlusion [3]. Isolated aortoiliac occlusive disease more commonly occurs in young female patients with a higher incidence of smoking and hypercholesterolemia as associated risk factors that portend a better prognosis. However, patients with a more multilevel pattern of the disease are commonly older males, and are more likely to have diabetes and hypertension as risk factors. These patients tend to have lower life expectancy $[4,5]$.

This case report illustrates the importance of early identification of patients with relevant risk factors and symptoms of aortic occlusion. An important early warning sign in this case was absence of distal pulses coupled with back pain. There are several similar reported cases which ended in varying outcomes depending on rapidity of diagnosis and treatment initiation [2, 3, 6, 7]. Patients classically present with a history of the following triad of symptoms: claudication, impotence and decreased lower limb pulses. Alternatively, patients may present with a variety of symptoms like leg pain or weakness, loss of sensation in the lower limb and back pain as in this case [3]. Neurologic findings may initially lateralize, delaying the imaging needed to make this diagnosis [6]. Risk factors include hypertension, diabetes mellitus, hyperlipidemia and smoking [7]. Management in this case is usually surgical, aimed at relieving the symptoms and prevention of thrombus propagation. Recent reports advocate the use of ultrasonography for fast detection of aortic occlusion in the emergency department. It is a quick, inexpensive and reliable method for trained providers and can save a lot of time in delivering the definitive treatment to the patient [8].

\section{CONCLUSION}

This case of an acute presentation of Leriche syndrome highlights the critical need for early diagnosis and risk factor assessment in determining the outcome. A high index of suspicion is required. Bedsides, ultrasonography may prove to be an effective tool in the diagnosis of Leriche syndrome in the emergency department that can be used to screen critical patients presenting with unique symptoms, saving valuable time and shortening the interval until the patient receives definitive care.

$* * * * * * * * *$

\section{Author Contributions}

Omar Sherif Askar - Conception and design, Acquisition of data, Analysis and interpretation of data, Drafting the article, Critical revision of the article, Final approval of the version to be published

Abdel H Noureldin - Conception and design, Acquisition of data, Analysis and interpretation of data, Drafting the article, Critical revision of the article, Final approval of the version to be published
Satish Chandrasekhar Nair - Conception and design, Acquisition of data, Analysis and interpretation of data, Drafting the article, Critical revision of the article, Final approval of the version to be published

\section{Guarantor}

The corresponding author is the guarantor of submission.

\section{Conflict of Interest}

Authors declare no conflict of interest.

\section{Copyright}

(C) Omar Sherif Askar et al. 2014; This article is distributed under the terms of Creative Commons attribution 3.0 License which permits unrestricted use, distribution and reproduction in any means provided the original authors and original publisher are properly credited. (Please see www.ijhpd.com/copyright-policy.php for more information.)

\section{REFERENCES}

1. Rene Leriche, Andre Morel. The syndrome of thrombotic obliteration of the aortic bifurcation. Ann Surg 1948;127(2):193-206.

2. Ozeren M, Kaya M, Kar M, Yücel E, Durmaz T. Coronary artery disease incidence between type II diabetic and non-diabetic patients with Leriche syndrome. Indian J Med Sci 2003;57(10):442-9.

3. Zankl AR, Blessing E, Volz HC, Krumsdorf U, Katus HA, Andrassy M. Neurological symptoms in acute Leriche's syndrome. Clin Res Cardiol 2010;99(7):45962.

4. Malone JM, Moore WS, Goldstone J. Life expectancy following aorto-femoral arterial grafting. Surgery 1977;81(5):551-5.

5. Darling RC, Brewster DC, Hallett JW Jr, Darling RC 3rd. Aortoiliac reconstruction. Surg Clin North Am 1979;59(4):565-79.

6. Schröder M, Friedrich K, Zipfel B, Gutberlet M, Möckel M. Acute painless paraplegia of the legs as a manifestation of extensive acute Leriche syndrome. Clin Res Cardiol 2007;96(4):240-2.

7. Frederick M, Newman J, Kohlwes J. Leriche syndrome. J Gen Intern Med 2010;25(10):1102-4.

8. Roxas R, Gallegos L, Bailitz J. Rapid detection of aortic occlusion with emergency Ultrasonography. Ann Emerg Med 2011;58(1):21-3. 


\section{ABOUT THE AUTHORS}

Articlecitation:AskarOS,NoureldinAH,NairSC.Acutepresentation ofLerichesyndromeintheUnitedArabEmirates: A case report. Case Reports International 2013;3:6-9.

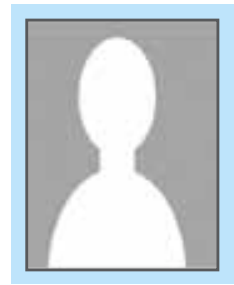

Omar Askar is a Resident at Department of Emergency Medicine Tawam hospital-Johns Hopkins Medicine International in $\mathrm{Al}$ Ain, UAE. His research interests include Pain control and Trauma management in the ED. He intends to pursue a fellowship in critical care after completing his residency.

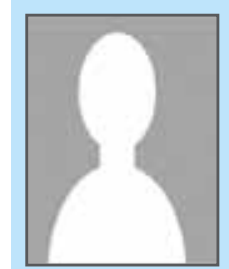

Abdel H Noureldin is Program director and Senior Consultant at Department of Emergency Medicine Tawam hospital-Johns Hopkins Medicine International in Al Ain, UAE. He is also adjunct Clinical Assistant Professor at the school of medicine, UAE University, UAE. He earned the undergraduate degree Bachelor of science from Loyola University, Chicago, Illinois, USA and postgraduate degree MD from Loyola stritch school of medicine, Maywood, Illinois, USA. Fellow, American College of Emergency Physicians Board Certified Emergency Room Physician. His research interests include Airway management and quality improvement.

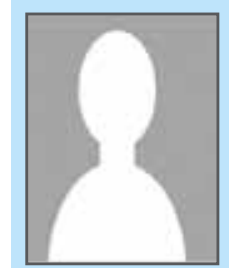

Satish C Nair is Senior Specialist and Head Clinical Research at the academic affairs Department of Tawam hospital-Johns Hopkins Medicine International in Al Ain, UAE. He earned Med. Bch. From TN Medical College, PhD from MBA from the University of Nebraska, USA. He also is a clinical associate professor at the school of medicine, UAE University, UAE. He has published 53 research papers in national and international academic journals and authored 2 book chapters. His research interests include molecular understanding of diseases, clinical trials and medical ethics.

Access full text article on other devices

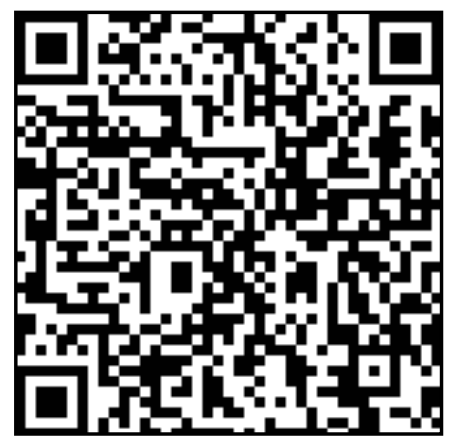

Access PDF of article on other devices

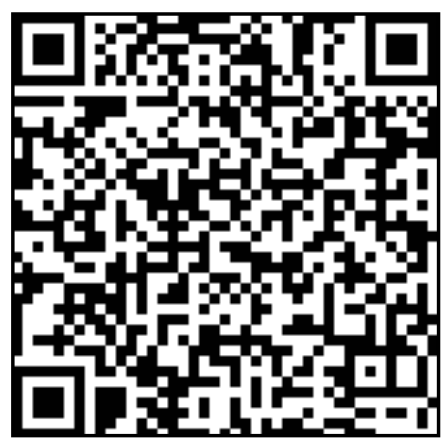

